\title{
Experiences and outcomes of a women's leadership development program: A phenomenological investigation
}

\author{
Krystal L. Brue \\ Assistant Professor, Organizational Leadership \& Business \\ Cameron University \\ Shawn A. Brue \\ Licensed Marriage \& Family Therapist and Licensed Professional Counselor \\ Christian Family Counseling Center \\ Lecturer, Psychology \\ Cameron University
}

\begin{abstract}
Women's leadership training programs provide organizations opportunities to value women leaders as organizational resources. This qualitative research utilized phenomenological methodology to examine lived experiences of seven alumni of a women's-only leadership program. We conducted semi-structured interviews to clarify what learning elements were most beneficial in furthering an individuals' leadership role. Emerging research themes included perceptional and personal agency changes within participants. Women's leadership programs provided an opportunity for cognitive, affective, and behavioral growth; engaging learning activities, social capital development, and relational model methodologies were perceived as most helpful in leadership development. Action learning techniques, fostering interconnectedness, and philosophical leadership development activities were critical elements in leadership development. Insights gained from this study provided perspective on the unique experiences of women in a leadership training program.
\end{abstract}

\section{Introduction}

Leadership development programs provide a vital component for promoting future operational growth (Dragoni, Park, Soltis, \& Frote-Trammell, 2014; Hirschfeld \& Thomas, 2011; Kim \& Thompson, 2012; Simmonds \& Tsui, 2010; Smith-Doerr et al., 2011). While numerous organizations provide leadership development training to high potentials, traditional leadership development programs have failed to meet the distinctive needs of women (Ely, Ibarra, \& Kolb, 2011; Hopkins, O'Neil, Passarelli, \& Bilimoria, 2008; Vinnicombe \& Singh, 2003).

Organizations that want to facilitate the emergence of new competent leaders have considered improving prospective women leaders through women's-only leadership development (WOLD) programs (Dreher, 2003).

Reasons why women are underrepresented in leadership are complex; Ely et al. (2011) theorized that male dominated organizational structures and gender bias business cultures that "equated leadership with behaviors believed to be more common or appropriate in men, powerfully if unwittingly communicate that women are ill-suited for leadership roles" (p. 475). Women were less integrated into dominant organizational coalitions and received less mentoring, reducing their likelihood of being tapped for higher status positions (Boatwright \& Egidio, 2003; 
Ely et al., 2011; Tessens, White, \& Web, 2011). Additional researchers (Anderson, Vinnicombe, \& Singh, 2008; Debebe, 2011; Hopkins et al., 2008; Vinnicombe \& Singh, 2003) contended that women face unique leadership challenges unmet by established leadership programs and endorsed the implementation of WOLD programs, which address specific developmental and instructional needs of women.

As leadership research continues to develop, the impact of post-participation in WOLD programs is incomplete. While theoretical literature based on the practical delivery of WOLD programs have been proposed, only preliminary empirical research has been conducted on the lived experiences and internalization of WOLD training. With increased implementation of WOLD programs, additional empirical research should be conducted on WOLD outcomes in a variety of contexts, the experiences of women who have participated in WOLD training, and the implementation of leadership training within their professional careers. Our study contributes to the emerging research by validating theoretical assumptions regarding WOLD programs. Additionally this study (a) provides specificity on how WOLD programs impact participants' personal agency and equip women for leadership growth, and (b) expounds on how alumni reflect on meaningful WOLD learning elements and integrate components post-training. WOLD programs, which address relational connectedness, interactive learning activities, philosophical and practical leadership development pursuits have the greatest impact on the development and advancement of women leaders.

\section{Literature Review}

Many organizations use comprehensive leadership training models, including developing communication, conflict management, team building, decision making, and employee engagement skills to proactively cultivate new leaders and improve the caliber of incumbent employees (Crumpton-Young, et al., 2010; Kim \& Thompson, 2012). With the demands to increase competitiveness, diversify leadership, and advance emergent leaders, organizations are increasingly developing WOLD programs (Ely et al., 2011). WOLD programs promote women by allowing them to experience transformational learning in a supportive environment (Debebe, 2011), learn from a majority position (Ely et al., 2011), maximize their unique learning strategies of collaboration while developing role models, networks, and mentors (Vinnicombe \& Singh, 2003), and manage the authenticity and balance of being true to themselves as well as an organizational leader (Anderson et al., 2008). The following literature review will examine general leadership development programs and the unique approaches used within WOLD programs.

Practices of General Leadership Programs. Numerous researchers (Dragoni et al., 2014; Garman, 2010; Rai \& Singh, 2013; Sirianni \& Frey, 2001) recommended using best practice instructional strategies when developing leadership programs including: (a) developing leadership competencies through learning experiences and expanded responsibilities, (b) participating in 360-degree feedback, (c) developing role knowledge, and (d) enhancing high potentials' exposure. These researchers also suggested the exposure of potential leaders to exceptional leader role models and mentors through behavioral modeling. 
Professional networking tactics were instrumental in developing a leader's potential, advancing careers, and expanding social/human relations values (Fredricks, 2003; Groves, 2007). Simmonds and Tsui (2010) suggested the use of multiple and integrated learning elements, such as networking, leadership workshops, multi-level feedback, and action learning afforded the greatest opportunity for behavioral implementation. Utilization of multiple learning strategies improved performance meritocracy, commitment to the organization's mission, work performance, and innovation management (Simmonds \& Tsui, 2010).

While many leadership training programs have successfully built a potential leader pipeline (Groves, 2007) by helping participants identify their personal leadership style (Fine, 2009), critics of leadership preparation programs have suggested that curriculum was often unconnected to real-life skills potential leaders need (Hackmann \& McCarthy, 2011). Despite development initiatives, customary leadership strategies can fail if subtle gender biases and a lack of women with leadership identities are present in an organization (Ely et al., 2011).

Women's-Only Leadership Development Training. Outcomes from traditional leadership programs have illuminated the negative consequences that occur when women are encouraged or expected to display perceived traditionally male leadership behaviors (Ely et al., 2011; Mandell \& Pherwani, 2003; Pratch \& Jacobowitz, 1996). Some leadership program designs are ineffective as they lack sound pedagogical framework unique to women (Ely et al., 2011). Delivering a program comparable to one delivered to men or implementing a learning strategy where women must be trained to assume male dominate leadership behaviors has proven counterproductive and victimized women for their different leadership tactics (Ely \& Meyerson, 2000; Gherardi \& Poggio, 2001). Although men and women have many leadership similarities, biological, neurological, psychological, and communication differences influence the way men and women process information, handle stress, relate to one another, and experience leadership (Ruderman \& Ohlott, 2005). Women are considered more likely than men to seek social contact in stressful situations, respond quicker to positive feedback, prompt personal and group improvements, blame themselves for poor performance, and use communication in collaborative ventures (Ruderman \& Ohlott, 2005). While many leadership training programs may value assertiveness, powerfulness, and the ability to be direct, these masculine modes of leadership often do not mesh well with distinctively relational and collaborative strategies utilized by women leaders (Berry \& Franks, 2010; Boatwright \& Egidio, 2003; Fine, 2009).

Ruderman \& Ohlott (2005) noted relational connections, authenticity, self-awareness, and personal agency are particularly essential for WOLD programs. Women who were provided opportunities to develop connectedness with other women, bolster leadership knowledge, as well as facilitate self-esteem were more likely to aspire for leadership opportunities than women who experienced traditional leadership orientations and experienced fears of negative evaluations (Boatwright \& Egidio, 2003). Women cited exclusion from vital networks and the inability to hear other women reflect on their leadership development as a hindrance to their personal leadership growth (Vinnicombe \& Singh, 2003). Hearing other women reflect on their leadership stories provided participants the affirming process of objectively reviewing their own struggles and identifying areas for leadership growth (Vinnicombe \& Singh, 2003). 
Offering a talent spotting mechanism, WOLD programs enhanced leadership development by providing a diverse framework involving personal assessment, formalized training, feedback opportunities, experiential learning, coaching, mentorship, and network development, which were gender distinctive and provided gender-sensitive instructional strategies (Debebe, 2011; Hopkins et al., 2008). Essential criteria for transformational leadership learning of women included learning from experienced women leaders, from the shared experiences of other women, and in a safe environment where women can express questions and concerns without fear of evaluation (Debebe, 2011). Additionally Debebe (2011) and Vinnicombe and Singh (2003) suggested that WOLD programs should complement other leadership initiatives and allow women to (a) personally develop and deeply assess their leadership philosophy; (b) build greater effectiveness in their present positions; (c) provide and receive feedback and coaching; (d) participate in collaborative and experiential learning; (e) develop knowledge and expertise as a leader; (f) connect with intentional mentors who provide candid and committed support; and (g) internalize confidence needed for leadership success. However, caution should be noted as placing a female leader within an impervious environment can quash any leadership growth potential (Debebe, 2011).

Theoretical Framework. Assessing WOLD programs can be viewed through several theoretical frameworks including resource dependence theory (RDT) (Pfeffer \& Salancik, 1978), social capital theory (Lin, 2001), and social learning/cognitive theory (Bandura, 1989). Drawing from RDT developed by Pfeffer and Salancik (1978/2003), offering leadership training minimized organizational dependence on external resources, while cultivating valued human capital. RDT allows researchers an interdependence framework to view organizational leadership development noting that organizations and leaders are co-dependent regarding crucial resources (Drees \& Heugens, 2013). Due to economic and environmental uncertainties, organizations can reduce risks by becoming proactive in their efforts to promote their human resources (Kim \& Thompson, 2012; Pfeffer \& Salancik, 1978/2003).

Because organizations are idiosyncratic entities with unique leadership assets, social capital resource development affects the operation of the organization and the functioning of individual leaders. Akingbola (2013) described social capital as the usefulness of associations within and outside of the organization. Social capital theory emphasizes the value of social networks, collaboration, and knowledge sharing (Kessels \& Poell, 2004). Lin (2001) and Kessels and Poell (2004) emphasized that leaders need social capital resources to perform well and thus organizations should foster social capital development for improved economic growth.

Emphasizing the learning process of becoming a skilled practitioner, social learning theorists view learning as a relational and discursive activity (Bandura, 1989; Jacobs \& Coghlan, 2005; Ponton \& Rhea, 2006). Bandura (1989) suggested that individuals are motivated by forethought of cognized goals, perceived self-efficacy, personal agency, and self-refection, learning from personal interaction or by observing modeled behavior. Self-efficacy and cognitive motivation played crucial roles in helping an individual achieve goals and reach desired outcomes (Ponton \& Rhea, 2006). Jacobs and Coghlan (2005) extended social learning theory by submitting that learning ensued with informal and conversational practice involving the application, reflective interaction, and competence development. 


\section{Methods}

Research Focus. Empirically examining the delivery of WOLD programs is essential because increasingly, organizations are implementing programs to specifically encourage women to reach their full workplace potential (Ely et al., 2011; Zahidi \& Ibarra, 2010). Utilizing a phenomenological method, we investigated the perceived experiences of alumni from the state of Oklahoma Career Tech Women in Leadership (OCTWL) program to clarify what learning elements were most beneficial in furthering an individual's leadership role and career advancement.

Connecting leadership with phenomenological research is still in its early stages (Cunliffe, 2009; Küpers, 2013). As a phenomenon of interest, participating in WOLD programs have not been a subject of ample empirical examination (Fine, 2009). Preliminary works were found that qualitatively assessed the experiences of individuals participating in WOLD programs including Stead (2014) who phenomenologically analyzed participants' reflections of action learning within a leadership program and Debebe (2011) who utilized a grounded theory methodology to deduce essential elements of transformational learning in WOLD programs. However, additional WOLD studies are needed to penetrate experiential meanings of this complex topic and further probe into the world of women leaders (Debebe, 2011; Fine, 2009).

Research Design. Based on the original research question, a phenomenological methodology was chosen to investigate how women assimilated and implemented their WOLD, providing true data and awareness about the investigated phenomena (Rendtorff, 2015). Phenomenology is often employed for the study of topics void of extensive research (Creswell, 2012) and the assumed aspects of life (Dahl \& Boss, 2005). A deeper and more comprehensive understanding of aspiring women leaders in a WOLD program can be used to improve the quality,, delivery and effectiveness of such programs.

Phenomenology as a methodology in the qualitative tradition attempts to gain knowledge and understanding by accessing individuals' lived experiences (Byrne, 2001) and describes these experiences using rich and authentic language (Moustakas, 1994). Phenomenologists strive to capture and articulate the fundamental nature of a particular human experience through contextually relevant and extensive interviews (Kvale \& Brinkman, 2009). A central focus of phenomenological research is the common knowledge and meaning of a group of people who have all experienced a particular phenomenon (Moustakas, 1994).

The general process of phenomenology (Moerer-Urdahl \& Creswell, 2004; Moustakas, 1994) includes (a) identifying a phenomenon of interest, (b) setting aside previous experiences and habitual ways of viewing the topic, (c) gathering data from people who have lived that phenomenon, (d) distilling that data into meaningful units, and (e) rendering a distilled essence of the experience for all participants (Creswell, 2012). With the phenomenon of interest chosen, we participated in bracketing (Creswell, 2012) processes to detect and set aside personal knowledge and previous experience with the phenomenon. The lead researcher is a former employee of the Career Tech system; however, neither researcher has an association with the OCTWL program. Data gathering, analysis, and essence aspects of the project will be discussed below. 
Research Setting. The OCTWL program was established in 2010 to create a leadership learning community for women within their educational system. The goal was to empower women to develop leadership strategies, provide a forum to share leadership insights, and address organizational challenges faced by women (Oklahoma Department of Career and Technology Education, 2014). Sessions focused on leading courageously, communicating effectively, influencing the organization, and thinking strategically. Approximately 20-25 women composed each class, meeting four times over a 10-month period. Three classes of women have completed this program.

Browne-Ferrigno and Muth (2012) highly recommended that leadership programs engage purposively in follow-up research. The examination of WOLD programs using phenomenology offers several benefits including understanding the essence of the experienced leadership learning as well as the internalization and transformation of WOLD training within the development of women leaders; evaluating WOLD program efficacy and outcomes is problematic and costly for organizations (Sirianni \& Frey, 2001). Qualitative measures can be employed to gain valuable insight into participants' experiences (Creswell, 2012).

Characteristics of Participants. Purposeful criterion sampling was used to select seven women who completed one of three WOLD programs conducted biennial since 2010; two alumni from class 1 and 3 were represented and three participants represented class 2. Data for this research were verbatim transcripts of seven in-depth telephone interviews conducted between 9 October and 17 November, 2014. Recognizing the limited availability of participants, focused interviews ranged from 30 to 45 minutes, for a total of 295 minutes, and consisted of all volunteer participants answering an invariant set of questions listed below. At the time of the interviews, all participants were employed in the Oklahoma Career Technology system. Their education ranged from Baccalaureate degree to a Doctoral student. With 113 total years of educational experience, their range of job experience was 10 years to 22 years (16 years average). Employment positions at the time of interview ranged from educators/counselors to assistant superintendent.

\section{Interview Protocol:}

1. In what way has your use of leadership changed since completing the training? How has participation in the program affected your leadership development?

2. How has your experience in the women leadership program enhanced your progression as a leader? What leadership development learning strategy was most beneficial to career progression?

3. When considering the program, what leadership learning elements did you perceive as most useful to your leadership roles?

4. What leadership technique taught was more helpful as a leader?

5. What was the overall value of this training program?

6. (Added) Do you feel women struggle in their leadership development? If so, why?

Questions were used to describe specific situations and actions and were determined based on leadership research conducted by Küpers (2013) regarding phenomenological leadership perspectives, Fine (2009) regarding narrative survey methodology on women leadership, Groves 
(2007) regarding WOLD practices, and Dragoni et al. (2014) regarding knowledge acquisition and behavioral development. Utilizing Giorgi's (1997) approach to phenomenological research, initial questions obtained descriptions of the experience and follow-up questions were used to elicit meaning. Exploration and clarification questions were asked to deepen the content of the interview and when elucidation was needed (Kvale \& Brinkman, 2009).

Data Collection and Analysis. The research study was reviewed and approved by the Director of the OCTWL program. The study was also approved by the university's Institutional Review Board prior to data collection and complied with ethical research standards.

Initially, 60 program graduates were contacted via email by the OCTWL program's director and invited to participate in the study. The lead researcher's contact information was included in the invitation email. Volunteers who responded to the lead researcher with a desire to participate were sent further information about the study's purpose and methods along with informed consent documents and were provided with a preliminary meeting to establish trust and orient participants with the research topic. Upon securing informed consent for participation, focus interviews were scheduled. Insuring participants of anonymity and confidentiality, interviews were conducted by the lead researcher at a time convenient for the participant and digitally recorded using pseudonyms. After interviews were conducted, verbatim transcripts were produced and checked for accuracy by both researchers as well as individual participants. These transcripts were then analyzed utilizing phenomenological methods (Moustakas, 1994). Finally, accuracy and validity of data collection/analysis was improved by a member-checking feedback process (Creswell, 2012). Identifying information was kept secure and disposed of after the project's completion.

We independently identified and cataloged significant words, statements, and phrases made by each participant. These were then synthesized to create clusters of meaning. A form of phenomenological reduction (Moustakas, 1994), clustering these significant statements and meaning units (Moerer-Urdahl \& Creswell, 2004; Moustakas, 1994) together in a variety of ways produced themes of common experience (Moustakas, 1994). With the inclusion of direct quotes from participants, these clusters of themes were rendered into a detailed description of participants' experience of the phenomenon (Creswell, 2012; Moustakas, 1994).

In keeping with the qualitative underpinnings of phenomenology, a strict validation strategy in the quantitative vain is not necessary (Creswell, 2009; Patton, 2002; Trochim \& Donnelly, 2008). Rigorous phenomenology does require quality and consistency in methodology (Marshall \& Rossman, 2011). While length and quantity of interviews are not mandidated, Giorgi (2009) stated, "what one seeks from a research interview in phenomenological research is a complete description as possible of the experience that a participant has lived though" (p. 122). The 295 minutes of focused interviews provided us with a rich and saturated description of experiences. While quantitative research utilizes internal and external validity, reliability, and objectivity as methods for judging research quality (Creswell, 2012), the concepts of credibility, transferability, dependability, and confirmability were selected as isomorphic counterparts (Lincoln \& Guba, 1985). Several quality assurance structures were utilized to create trustworthy results, including member-checking, contextualization, detailed descriptions, and bracketing (Lincoln \& Guba, 1985; Maxwell, 2005; Moustakas, 1994). 
Member-checking activities (Maxwell, 2005; Schwandt, Lincoln, \& Guba, 2007) heightened credibility and trustworthiness of findings by allowing the participants to judge the legitimacy of the results. All participants were provided their verbatim interview transcript including questions and responses, a list of meaningful statements, and our initial combined analysis. Feedback from each participant was received and member-checking activities contained no substantive changes. Readers desiring to transfer findings to other contexts (Lincoln \& Guba, 1985) are aided by the detailed description of data gathering and analysis processes provided. The utilization of thick, detailed descriptions of experience, authentic language, and direct quotes (Berrios \& Lucca, 2006; Moustakas, 1994) addressed dependability concerns by allowing participants to define concepts for themselves (Smith, Flowers, \& Larkin, 2009) and situating them within the native context (Finlay, 2011). Bracketing processes addressed concerns about confirmability by situating each researcher's unique perspective to the study (Schwandt et al., 2007) and clarifying researcher bias (Creswell, 2012).

\section{Reflection of Key Themes}

Our analysis yielded seven major themes and several sub-themes. Significant statements and meaning units were distilled to central topics and discussed below. A complete list of themes and additional supporting quote data is included below.

Theme 1: External/Positional - Changes in the Experience of Leadership. All participants acknowledged professional outward changes in their work position or perceptional status. Two participants were promoted after the training and all participants ascribed to improved productivity with their current role and increased preparedness for future leadership roles. Extending Fine's (2009) research, participants noted that they wanted leadership roles because they felt they had expertise and improved resources to make a more effective leader.

Participants 3, 4, and 5 reflected on how ill prepared they were within previous leadership roles, while Participant 4, 5, 6, and 7 noted how their current work tasks were viewed more "strategically," "insightfully," and "productively." Participant 5 stated, "I don't know that I have taken on new responsibilities, as much as I have stepped up in the one that I already had" and Participant 4 remarked

In my past leadership role, I didn't have any leadership training, and I was young... there was a lot of things that I wasn't ready for. Even though I am not in a leadership role right now, if that opportunity ever came about, I feel I would handle the situation and the things so much better because of the training.

Theme 2: Internal/Empowerment - Changes in the Personal Agency of Leadership. Previous research noted the negative effects of a lack of self-confidence common to women leaders (Sturm, Taylor, Atwater, \& Braddy, 2013). Several core and follow-up questions addressed how participation in the OCTWL program affected their leadership development, confidence, and self-awareness. All of the participants noted changes with self-efficacy and personal growth. Participant 5 commented "Getting the opportunity to see these other women and what they do really empowered me in stepping up to my potential." In addition, confidence, validation, and advocacy were predominantly mentioned throughout the interviews as perceived 
personal agency changes.

Participants 1, 2, 4, and 5 observed a significant increase in "confidence," with improved skills in dealing with "difficult situations," "hearing and trusting inner strength," and "managing doubts." Participant 6 stated:

It gave me a new level of confidence, it confirmed things that I had thought, but maybe I needed cemented a little more. I think a stronger confidence in what I do every day in helping and being a mentor was enhanced by the experience.

In addition, training encouraged participants to advocate for themselves by making strategic decisions, asserting themselves, and feeling emboldened to verbalize thoughts while working beyond stereotypical labels. Many participants acknowledged how the training authenticated their leadership desire. While one participant indicated that she may not seek future advance leadership roles, the remaining interviewees recognized how the training helped to conquerfears and facilitated leadership development.

Theme 3: Equipping Growth in the Areas of Cognition, Affect, and Behavior. A comprehensive list of valued outcomes and meaningful elements was accredited to program participation. Key elements centered on the need for a comprehensive approach to leadership training covering diverse tools and resources as well as addressing leadership thinking, feeling, and acting. Participant 5 acknowledged how the training gave her tools to honestly recognize her strengths and the fortitude to use them; she summed it by saying:

For me learning to hear my voice, that inner message and transcript that we all have ongoing. Sometimes the leader that I knew I would be, was over-ridden with the selfdoubts and with uncertainties that I felt my message was not as valid as the next person's. I think the tools that they gave me, helped me to learn to listen, look for those opportunities to step into a situation or moment and take charge of it. For me it was finding a way to hear myself.

Expanding on the personal development behavioral changes found in Boaden's (2006) leadership development research, participants overwhelming mentioned the value of self-awareness and self-reflection when identifying and confirming their leadership philosophies and gaps. Participant 2 stated "One of the most important things for me is self-reflection. What is my leadership style and what gaps are there?"

Recognition of cognitive, affective, and behavioral elements were substantially noted in all interviews. Being vision-oriented, improving communication and listening skills, acting strategically, being holistic in work and non-work roles, becoming purposeful as a problemsolver, conflict manager, and decision maker, as well as managing time and resources effectively were repeatedly mentioned. Additionally, interviewees revealed the significance of developing skills in managing "crucial conversations." Participants 2, 3, 4, and 7 specifically mentioned the value in learning how to manage critical conversations and the benefit of taking care of conversations earlier rather than later. 
Theme 4: Engage Learning Elements. Interviewees were asked to discuss what learning strategies were most meaningful. Based on responses, participants valued applicable and authentic learning elements. While participants noted role-plays, scenario based discussions using "real life" issues, small group discussions, and book/article analyses, each of the interviewees felt that hearing the uninhibited idea exchange from senior leaders as well as peer participants were the most valuable. Participant 2 noted "women don't see enough role models in leadership positions." Referring to those experienced speakers as "veterans," "those whohave gone before," and "women who broke the mold," interviewees discussed how smart, strong, and un-intimidated these women appeared. Participant 6 stated:

They truly were trailblazers for women as far as being accepted in the men's club, if you will. We have, not that same opportunity, but we have opportunities every day to be who we are and still make a difference and blaze a trail for those who will come behind us.

Within this leadership study, the value of hearing from real, authentic leaders allowed participants to normalize women leader styles, while valuing a leadership approach of caring and nurturing women. Whatley, Popa, and Kliewer (2012) also found that interactive, collaborative, and experiential learning activities significantly enhanced individual leadership learning. Additionally, Michailova and Sidorova (2011) concurred that group-based communication collaborations improved knowledge sharing and learning. When discussing the value of these real connections within our study, Participant 1 said, "She patted me on the back and said 'of course you could do it.' That was huge coming from someone of her status."

Theme 5: A Relational Model for Leadership is Essential. A substantial theme was the beneficial impact of establishing social capital associations, women leadership networks, mentorship connections, and leadership modeling. The value of listening and connecting with other women with similar stories was considerable in the quest for leadership development and instrumental in alleviating fears and concerns. Participant 4 noted, "The people that you meet was the biggest thing for me." Participants noted that WOLD training promoted co-orientation, allowing them to find cohorts and colleagues of "women going the same direction." These social capital connections provided relational equity, information resources, and collaboration venues.

Couched close to networking elements were discussions of mentorship. Learning from real, inspirational women both inside and outside the industry fostered growth. Participant 3 stated the value of hearing "personal stories of how they triumphed over sexism, being passed over, being considered less than... and how/what they did about it." Seen as forging the way, the women role models became coaches, champions, cheerleaders, and guides, sharing their personal journey of how they were able to move past obstacles.

Additionally, networking, mentoring connections, and leadership modeling allowed women to solidify an informal system outside their individual organizations. Participant 2 observed:

For me, it's the relationships that have been built throughout the system. I have more resources and people to call. For me personally, when I was applying for the job that I am in now, I contacted several of those key contacts, asking them to be references. I got 
information from them. Asking them what aspects should I be working on to be in this role. Resources... Networks.... All of that.

Alike to Dragoni's et al. (2014) and Bouchamma, Kalule, April, and Basque's (2014) findings, participants noted that the use of successful leader modeling and social capital resources improved overall role knowledge application and implementation.

Theme 6: Leadership Training Can Have Encompassing Impact on Employees. Imbedded within all interviews was the meaningful, life-changing impact of the overall program. Descriptive terms such as "meaningful" and "profound" were repetitively used to describe the leadership development process. Although participants noted the personal development work required to participate in this program and the positive/negative impact of conducting training away from their offices, participating in this program promoted skill development, career enhancement, and improved leadership aptitude.

Many interviewees commented on "aha" moments of self-discovery, validation of leadership approaches and philosophies, and the leadership identity transformation that occurred during the training. Participant 5 noted:

We all struggle with our identity in some way, whether we're comparing ourselves to other women, feeling like we come up short because we don't have this or that skill or ability, because we aren't this type of personality - we second guess ourselves constantly. Women are more prone to do that than men. Participating in this, solidified for me, my understanding of what I do have to offer, what I can bring to the table.

Related discoveries were noted in Boaden (2006), where leadership development programs have meaningful impact on personal development with continued influence on an individual's role and career progression and in DeRue and Ashford (2010), where leadership development was relationally recognized and collectively endorsed during social influence processes.

Emergent Theme 7: Perceived Struggle of Women. During the initial interviews, the lead researcher noted interviewees alluded to the reasons why women struggled at work. Statements including "not being ashamed of being a women" (Participant 3) and "bias toward strong women" (Participant 5) as well as the contrast between traditional male and female modes of leadership were shared thoughts. Therefore, in subsequent interviews, participants were asked why they perceived women grapple with their leadership development.

Prior to the program, each of the women perceived a lack of women role models and had experienced gender infused stereotypes within their perspective workplaces. Participant 7 indicated:

Several reasons, I mean the inequality and pay. Women aren't always valued. If we take charge, we're bitchy, and if a man takes charge, he's respected. If he gets gray hair around his ears, he's distinguished, if I get gray hair, I'm getting old. We need to break those stereotypical thoughts. 
Chugh and Sahgal (2007) concurred and described sex-role orientation and gender stereotyping as common issues that plagued emerging women leaders.

Other interviewees noted that empathy toward others may hamper their leadership progression and according to their experience, women leaders are viewed differently than men. Participants noted the learning process of realizing the negative cycle of comparing women leaders to male leaders and the need to embrace their uniqueness and strength-based approaches. Participants felt that to advance in leadership roles, they needed to celebrate their differences.

\section{Themes with Supporting Participant Quotes:}

\section{External/Positional - Changes in the Experience of Leadership}

- It's just a matter of learning my own strengths - and go ahead and step into those strengths and not allow myself to stand in the background as much. To be willing to step forward more (Participant 5).

- It's a program that will help you refine and define your leadership skills. It will expand ways of knowing things, and how to network with other people in more effective ways, help you to develop your leadership philosophy and kind of layout some concrete ideas on how to move forward (Participant 3).

2. Internal/Empowerment - Changes in the Personal Agency of Leadership

- It helps women collectively and individually learn to look insightfully into themselves and draw upon their strengths. We don't always recognize what we have and can bring to the table; we down play it. (Participant 5)

- I know that I have a strong personality, that doesn't always lend well to leadership because you have to learn what's important when you are leading people is not as important as having a strong personality. You must allow other people to be strong and shine that you look to other ways to serve other people even as a leader (Participant 5).

- I don't have to be something that I am not in order to be who I am. (Participant 5).

- Getting out of the work routine that I had gotten into -- it's kind oflike when your children go off to camp - they come back different people. I was able to go off and come back different as well - it takes courage and after you get it done, you feel more courageous and not so afraid to do it the next time (Participant 7).

\section{Equipping Cognition, Affect, and Behavior Growth}

- So now, when I have to have critical conversations, I have some tools that I can use. I can consider what are some of those elements I must cover in the conversation, giving the other person space when seeing what the issue is. This training has given me some of those tools to use (Participant 2).

- So my philosophy of leadership was definitely validated that to be a good leader you need to serve others (Participant 7). 
- I recognize the strengths that each of us have that are different, but they each play a crucial role in leadership and in creating a strong leadership program for any organization or school (Participant 5).

\section{Engage Learning Elements}

- Book discussion and presenters stood out for me - interactions and activities helped the most. There was one training on accepting differences, and understanding about what's going on in a person's life before they have arrived where they are. This helps you to understand the reactions they have to things in the work force, and the activity was really neat. (Participant 7).

- The program is a wonderful opportunity for women to network, grow, and strengthen their leadership skills, it's a wonderful way to learn from others' experiences and bounce your ideas and expertise and get gain from others and they gain from you, it's just a wonderful growth opportunity (Participant 4).

\section{Relational Model for Leadership is Essential}

- I know that if I had a problem, I would pick up the phone, I would have people all across the state doing the exact same thing that I do and they would be able to tell me what they have done in that situation, or what somebody else at their center had done for whatever. The networking part of it was incredible. Absolutely, the people that you meet, is one of the biggest things for me (Participant 4).

- It's bigger than networking. It allows us to build a system and collaborate across the system (Participant 2).

- It's awesome to be able to have this network statewide... I think the networking and relationships will be lifelong resources for us as we grow and develop in our leadership roles (Participant 5).

- The confidence that it gives you and the connections. Ask those questions and how did you deal with this, and what would you do, to have that mentorship relationship was the best thing about it (Participant 4).

- We have met together since then; we've been in activities together since then. I think it was a real defining opportunity to click with women we otherwise would not have (Participant 5).

\section{Encompassing Impact of Leadership Training}

- My girlfriend says since that leadership thing, I am much better at letting things roll off; I don't take things so personally anymore. Not in a bad way, but I attack it with a solution in mind, and not beating myself up over it (Participant 7).

- It's the single best leadership training that I have been involved in. An awesome experience - I'd even go as far as to say a life changing experience. Not only did it reinforce ideas about leadership, but I made lasting relationships with the people in the class (Participant 6).

\section{7. (Emergent) Perceived Struggle of Women}

- We have this sense about us that men don't have. We care, about their feelings, if we fire this person, then, they don't have a pay check, then 
their kids suffer that stuff all relates to us... when probably if they are in that type of situation and they're not doing their job, I think men might have a better time at separating that (Participant 4).

- We have to defend our right to step outside our home, especially if you are stepping into a role of leadership...there is still a lot of inequality and bias against strong women (Participant 5).

- Women have allowed life to slow their progression in leadership roles (Participant 6).

\section{Synthesis and Essence of Experiences}

Women who participated in the OCTWL program gained an increased sense of being prepared for leadership, seeing leadership as less of an occupied position and more of a mindset. They felt more equipped for advancement to leadership positions, which in some cases they had already assumed but were also aware of the leadership potential in their current level of responsibilities. Overwhelmingly, they felt better prepared to assume leadership roles if the opportunities arose. This preparedness goes beyond gaining leadership skills and had a personal growth aspect to it. Class participants gained confidence and grew in personal agency, believing that if other women can achieve high places of leadership, they could succeed as well. Experiencing the leadership program validated desires to be in leadership and helped them to believe that they have the requisite skills and abilities to do well in those positions.

Participants experienced a broad range of training elements that were meaningful. These elements were comprehensive and addressed the cognition, affect, and behavior of leadership development. With an array of skill-building activities, participants valued elements as diverse as vision development, problem solving, skillfully conducting critical conversations, managing anxiety, and purposefully taking action. These highly regarded competencies were taught using authentic and practical methods, including experienced women leader speakers, role-playing and scenario-based discussions, small group interaction, and book/article analysis.

Participants found that connecting with other women associated with the leadership program was deeply meaningful. Alumni placed immense value on building networks and having informational and encouragement mentors. With these relational assets, most felt less fear and more courage when considering further leadership pursuits. For program participants, the inspiration and collaboration gained from these relationships was generative. As participants reflected on their experience of the leadership program, they realized what a life-changing set of experiences it was. From developing connections with other women to building and validating philosophies of leadership, the program had made them better leaders. This improvement was especially germane given that dominate contemporary leadership philosophies seem to trend toward traditionally masculine characteristics. Learning and practicing leadership processes that tap into qualities that are more traditionally feminine were validating and formative.

\section{Application}

This study's objective was to investigate the perceived outcomes and experiences from a WOLD program to clarify what learning elements were most beneficial in furthering an 
individual's leadership role. Results suggest several key elements, which are essential for transformational WOLD programs.

Fostering Systemic Relationships and Interconnectedness. As with Boatwright and Egidio (2003), Garman (2010), and Kim and Thompson (2012), results revealed the importance of viewing leadership development as a systemic program positively affecting the organization and individual. The interconnectedness and social capital resources among leaders, their organizations, and their peers fostered knowledge, skill, and talent development. All interviewees saw relationships, networking, mentoring, and informational connections as vital to leadership development. The collective endorsement of participants co-developing in a social environment reinforced a strong and stable desire to improve their leadership confidence.

Behavioral Modeling. Roles models used throughout WOLD training provided participants with relational support and role knowledge, confirming leadership development as a social learning process. Results from our study paralleled previous literature (Karelaia \& Guillén, 2014) on the importance of organizational attitudes toward women and supporting mentoring practices, which can strengthen women's leadership identities. Additionally, Dragoni et al. (2014) noted the interactive effectiveness of senior leaders who both showed and told how they became a leader; this process enhanced the progress of women transitional leaders' selfperceived leadership acquisition. Dragoni et al. (2014) stated that transitioning leaders need to have a model of leadership development especially if they have not been exposed to an exceptional leader in their career. Participants within this study craved women mentorship relationships with senior leaders who shared their stories and imparted wisdom. These women trailblazers provided authentic and descriptive examples of effective leadership behaviors and functional clarity.

Finding a Voice and Selling a Vision. Women leaders must find their own voice and communicate their vision despite fears or barriers. These fears or social factors can make it difficult for women to share their vision or step into leadership roles without sounding boastful or harsh. Participants noted the value of learning how to promote a balanced approach when performing corrective actions, managing conflict, leading personnel, and sharing their vision. Similarly, Ibarra and Ododaru (2009, p. 64) noted that "one of the biggest developmental hurdles that aspiring leaders, male and female alike, must clear is learning to sell their ideas." Within leadership progression, developing a vision necessitates a future and strategic focus (Grant \& Taylor, 2014). Program participants stated the value of developing, solidifying, and mapping their leadership philosophy. Several participants noted the critical moment of seeing their philosophy in writing, using it to visualize how they would professionally grow, and verbalizing it in their workplace.

Personal Agency. Personal agency, the desire to act assertively and confidently on one's own behalf, is a dominant need of high-achieving women leaders (Ruderman \& Ohlott, 2005). Program participants noted doubts or a lack of self-confidence as a common barrier; however, participants stated increased feelings self-efficacy, confidence, and overall validation of their leadership potential as a result of WOLD involvement. Additionally, self-perception, confidence, and developmental efficacy appeared to be catalysts of leadership development. 
Cognitive, Affective, and Behavioral Emphasis. Participants noted the significant impact of cognitive, affective, and behavioral changes within their leadership identity. Selfawareness and self-reflection opportunities as well as challenges to the way participants think, process, feel, and act helped to solidify their leadership values, styles, and vulnerabilities. Comparably, Ruderman and Ohlott (2005) noted that "self-clarity allows women to grow by enabling them to recognize their values so they can live authentically, improve their ability to connect with others, enable their own agency, and make choices that produce feelings of wholeness" (p. 9). Cognitive, affective, and behavioral changes helped to construct and solidify participants' leadership identities, which are essential as participants integrate their new skills within the workplace.

Action Learning. Social learning strategies used in leadership development not only disseminated valuable knowledge and skills but also resulted in changed personal perceptions, attitudes, and behaviors. Sirianni and Frey (2001) suggested the value of using a mental model and action learning strategies where changes in thoughts drove changes in behaviors. Similar to Stead (2014), we found that facilitating an action-learning environment, where woman can connect with authentic leaders, cultivate peer-learning connections, and seek to develop without fear of exposure promoted the best quality environment for learning potential. Additionally our participants indicated the impact of context-specific scenarios and authentic experiences, which helped facilitate learning and internalize their leadership identity.

\section{Strengths, Weaknesses, Future Research, and Conclusion}

This study contributes to emerging research by validating current theoretical literature on WOLD programs and clarifying how WOLD programs impact authenticity and agency, as well as cognitive, affective, and behavioral development of women leaders. Additionally we examined the leader implementation process and identified learning elements, which influenced leadership implementation post-training. Strengths of this phenomenological study include its validation of theoretical premises on WOLD programs, clarification the impact of these programs, analysis of interactive and gender sensitive learning elements for post-training leadership implementation, as well as identification of further research avenues. The current study's main limitation is nested in its qualitative design. Although considered a strength for gleaning deep and detailed descriptions of personal experience and meaning (Byrne, 2001, Moustakas, 1994), the homogenous and limited sample size of the study may restrict generalizability (Byrne, 2001; Creswell, 2012). Although the synthesis of general themes and the cumulative essence gained from the study apply well to this sample of aspiring women leaders, transferability to other settings is cautioned (Yardley, 2012).

Another important limitation is the assumption that the participants in this research study could provide a rich and accurate description of their experiences with the phenomenon. Relying on research subjects' ability to recall and convey their experiences to the researcher has been called a representational validity of language (Willig, 2008). Our use of prolonged engagement, authentic language, and member-checking procedures mitigated potential data inaccuracies and produced findings true and trustworthy to participants' lived experiences (Creswell, 2012;

Schwandt et al., 2007). 
Several recommendations for further study are offered. WOLD research should be expanded to other programs and venues to seek further verification of findings. In addition, applying additional grounded theory methodology to the study of WOLD programs may aid in building cogent theory and strengthen applicability of training elements. Mixed methods that included survey research, other qualitative tools, and longitudinal studies may increase the generalizability of findings to other contexts. Finally, the use of quasi-experimental and/or experimental designs could strengthen correlational data on various leadership development programs of same-sex and co-educational cohorts.

Clarifying what learning elements were most beneficial in furthering women's leadership roles was the purpose of this research. A phenomenological approach allowed us to understand WOLD participants lived experiences. Discovered themes included perceptional and personal agency changes. Participants indicated that WOLD programs provided opportunities for authentic cognitive, affective, and behavioral growth, and should be centered on engaging learning activities as well as relational model methodologies. Action learning techniques, behavioral modeling, fostering interconnectedness, and philosophical leadership development activities will continue to help women reach their full potential.

\section{References}

Anderson, D., Vinnicombe, S., \& Singh, V. (2008). Women only leadership development: A conundrum. In K.T. James, \& J. Collins (Eds.), Leadership learning: Knowledge into action (pp. 147-161). London, Palgrave Macmillan.

Akingbola, K. (2013). Resource-based view (RBV) of unincorporated social economy organizations. Canadian Journal of Nonprofit and Social Economy Research, $4(1), 66-85$.

Bandura, A. (1989). Human agency in social cognitive theory. American Psychologist, 44(9), 1175-1184.doi:10.1037/0003-066X.44.9.1175

Berrios, R., \& Lucca, N. (2006). Qualitative methodology in counseling research: Recent contributions and challenges for a new century. Journal of Counseling and Development, 84, 174-186.

Berry, P., \& Franks, T. J. (2010). Women in the world of corporate business: Looking at the glass ceiling. Contemporary Issues In Education Research, 3(2), 1-9.

Boaden, R. J. (2006). Leadership development: Does it make a difference? Leadership \& Organization Development Journal, 27(1), 5-27. doi:10.1108/01437730610641331

Boatwright, K. J., \& Egidio, R. K. (2003). Psychological predictors of college women's leadership aspirations. Journal of College Student Development, 44(5), 653-669. 
Bouchamma, Y., Kalule, L., April, D., \& Basque, M. (2014). Implementation and supervision of the professional learning community: Animation, leadership and organization of the work. Creative Education, 5(16), 1479-1491.

Browne-Ferrigno, T., \& Muth, R. (2012). Call for research on candidates in leadership preparation programs. Planning \& Changing, 43(1/2), 10-24.

Byrne, M. M. (2001). Understanding life experiences through a phenomenological approach to research. Association of Operating Room Nurses. AORN Journal, 73(4), 830-832.

Chugh, S., \& Sahgal, P. (2007). Why do few women advance to leadership positions? Global Business Review 8(2), 334-350. doi:10.1177/097215090700800209

Creswell, J. W. (2009). Research design: Qualitative, quantitative, and mixed methods approaches (3rd ed.). Los Angeles, CA: Sage.

Creswell, J. W. (2012). Qualitative inquiry \& research: Choosing among five approaches (3rd ed.). Los Angeles, CA: Sage.

Crumpton-Young, L., McCauley-Bush, P., Rabelo, L., Meza, K., Ferreras, A., Rodriguez, B., \& ... Kelarestani, M. (2010). Engineering leadership development programs: A look at what is needed and what is being done. Journal Of STEM Education: Innovations \& Research, 11(3/4), 10-21.

Cunliffe, A. L. (2009). The philosopher leader: On relationalism, ethics and reflexivity A critical perspective to teaching leadership. Management Learning, 40(1), 87101. doi:10.1177/1350507608099315

Dahl, C. M., \& Boss, P. (2005). The use of phenomenology for family therapy research: The search for meaning. In D. H. Sprenkle, \& F. P. Piercy (Eds.). Research methods in family therapy (3rd ed., pp. 63-84). New York, NY: Guilford.

Debebe, G. (2011). Creating a safe environment for women's leadership transformation. Journal of Managerial Education, 35(5), 679-712. doi:10.1177/1052562910397501

DeRue, D. S., \& Ashford, S. J. (2011). Who will lead and who will follow? A social process of leadership identity construction in organizations. Academy of Management Review, 35(4), 627-647.

Dragoni, L., Park, H., Soltis, J., \& Forte-Trammell, S. (2014). Show and tell: How supervisors facilitate leader development among transitioning leaders. Journal of Applied Psychology, 99(1), 66-86. doi:10.1037/a0034452 
Drees, J., \& Heugens, P. (2013). Synthesizing and extending resource dependence theory: A meta-analysis. Journal of Management, 39(6), 1666-1698.

doi:10.1177.0149206312471391

Dreher, G. F. (2003). Breaking the glass ceiling: The effects of sex ratios and work-life programs on female leadership at the top. Human Relations, 56(5), 541-562. doi:10.1177/0018726703056005002

Ely, R. J., Ibarra, H., \& Kolb, D. M. (2011). Taking gender into account: Theory and design for women's leadership programs. Academy of Management Learning \& Education, 10(3), 474-493. doi:10.5465/amle.2010.0046

Ely, R. J., \& Meyerson, D. E. (2000). Theories of gender in organization: A new approach to organizational analysis and change. Research in Organizational Behavior, 22, 103-151. doi:10.1016/S0191-3085(00)22004-2

Fine, M. G. (2009). Women leaders' discursive constructions of leadership. Women's Studies In Communication, 32(2), 180-202. doi:10.1080/07491409.2009.10162386

Finlay, L. (2011). Phenomenology for therapists: Researching the lived world. Chichester, West Sussex: John Wiley \& Sons, Ltd.

Fredricks, S. M. (2003). Creating and maintaining networks among leaders: An exploratory case study of two leadership training programs. Journal of Leadership \& Organizational Studies Summer, 10(1), 45-54.

doi:10.1177/107179190301000104

Garman, A. N. (2010). Leadership development in the interdisciplinary context. In B. Freshman, L. Rubino, \& Y. Reid Chassiakos (Eds.), Collaboration Across the Disciplines in Healthcare (pp. 43-64). Sudbury, MA: Jones and Barlett.

Gherardi, S., \& Poggio, B. (2001). Creating and recreating gender order in organizations. Journal Of World Business, 36(3), 245-259. doi:10.1016/S1090-9516(01)00054-2

Giorgi, A. (2009). The descriptive phenomenological method in psychology: A modified Husserlian approach. Pittsburgh, PA: Duquesne University Press.

Giorgi, A. (1997). The theory, practice, and evaluation of phenomenological method as a qualitative research practice procedure. Journal of Phenomenological Psychology, $28(2), 235-260$.

Grant, A. D., \& Taylor, A. (2014). Communication essentials for female executives to develop leadership presence: Getting beyond the barriers of understating accomplishment. Business Horizons, 57(1), 73-83.

doi:10.1016/j.bushor.2013.09.003 
Groves, K. (2007). Integrated leadership development and succession planning best practices, Journal of Management Development, 26(3), 239-260.

doi:10.1108/02621710710732146

Hackmann, D., \& McCarthy, M. (2011). Clinical faculty in educational leadership programs: A growing force. Planning \& Changing, 42(3/4), 183-208.

Hirschfeld, R. R., \& Thomas, C. H. (2011). Age- and gender-based role incongruence: Implications for knowledge mastery and observed leadership potential among personnel in a leadership development program. Personnel Psychology, 64(3), 661-692. doi:10.1111/j.1744-6570.2011.01222.x

Hopkins, M. M., O'Neil, D. A., Passarelli, A., \& Bilimoria, D. (2008). Women's leadership development strategic practices for women and organizations. Consulting Psychology Journal: Practice And Research, 60(4), 348-365. doi:10.1037/a0014093

Ibarra, H., \& Obodaru, O. (2009). Women and the vision thing. Harvard Business Review, 87(1), 62-70.

Jacobs, C., \& Coghlan, D. (2005). Sound from silence: On listening in organizational learning. Human Relations, 58(1), 115-138. doi:10.1177/0018726705050938

Karelaia, N., \& Guillén, L. (2014). Me, a woman and a leader: Positive social identity and identity conflict. Organizational Behavior and Human Decision Processes, 125(2), 204-219. doi:10.1016/j.obhdp.2014.08.002

Kessels, J. W. M., \& Poell, R. F. (2004). Andragogy and social capital theory: The implications for human resource development. Advances in Developing Human Resources, 6(2), 146-157. doi:10.1177/1523422304263326

Kim, T., \& Thompson, J. M. (2012). Organizational and market factors associated with leadership development programs in hospitals: A national study. Journal Of Healthcare Management, 57(2), 113-131.

Küpers, W. M. (2013). Embodied inter-practices of leadership - Phenomenological perspectives on relational and responsive leading and following. Leadership, 9(3), 335-357. doi:10.1177/1742715013485852

Kvale, S., \& Brinkman, S. (2009). Interviews: Learning the craft of qualitative research interviewing (2nd ed.). Thousand Oaks, CA: Sage.

Lin, N. (2001). Social capital: A theory of social structure and action. Cambridge, UK: Cambridge University Press. 
Lincoln, Y. S., \& Guba, E. G. (1985). Naturalistic inquiry. Beverly Hills, CA: Sage.

Mandell, B., \& Pherwani, S. (2003). Relationships between emotional intelligence and transformational leadership: A gender comparison. Journal of Business and Psychology. 17(3), 387-404. doi:10.1023/A:1022816409059

Marshall, C., \& Rossman, G. B. (2011). Designing qualitative research (5th ed.). Los Angeles, CA: Sage.

Maxwell, J. A. (2005). Qualitative research design: An interpretive approach (2nd ed.). Thousand Oaks, CA: Sage.

Michailova, S., \& Sidorova, E. (2011). From group-based work to organizational learning: the role of communication forms and knowledge sharing. Knowledge Management Research \& Practice, 9, 73-83.

Moerer-Urdahl, T., \& Creswell, J. W. (2004). Using transcendental phenomenology to explore the "ripple effect" in a leadership mentoring program. International Journal of Qualitative Methods, 3(2), 19-35. Retrieved from http://ejournals.library.ualberta.ca/index.php/IJQM/article/view/4470/3594

Moustakas, C. (1994). Phenomenological research methods. Thousand Oaks, CA: SAGE.

Oklahoma Department of Career and Technology Education (2014). CareerTech Women in Leadership. https://www.okcareertech.org/

Patton, M. Q. (2002). Qualitative research and evaluation methods (3ed ed.). Thousand Oaks, CA: Sage.

Pfeffer, J., \& Salancik, G. (1978/2003). The external control of organizations: A resource dependency perspective. Stanford, CA: Stanford University Press.

Ponton, M. K., \& Rhea, N. E. (2006). Autonomous learning from a social cognitive perspective. New Horizons in Adult Education \& Human Resource Development, $20(2), 38-49$.

Pratch, L., \& Jacobowitz, J. (1996). Gender, motivation, and coping in the evaluation of leadership effectiveness. Consulting Psychology Journal: Practice And Research, 48(4), 203-220. doi:10.1037/1061-4087.48.4.203

Rai, H., \& Singh, M. (2013). A study of mediating variables of the relationship between $360^{\circ}$ feedback and employee performance. Human Resource Development International, 16(1), 56-73. doi:10.1080/13678868.2012.740797 
Rendtorff, J. D. (2015). Case studies, ethics, philosophy, and liberal learning for management profession. Journal of Management Education, 39(1), 36-55. doi:10.1177/1052562914562282

Ruderman, M. N., \& Ohlott, P. J. (2005). Leading roles: What coaches of women need to know. Leadership in Action, 25(3), 3-9.

Schwandt, T. A., Lincoln, Y. S., \& Guba, E. G. (2007). Judging interpretations: But is it rigorous? Trustworthiness and authenticity in naturalistic evaluation. New Directions for Program Evaluation, 114, 11-25. doi:10.1002/ev.223

Simmonds, D., \& Tsui, O. (2010). Effective design of a global leadership programme. Human Resource Development International, 13(5), 519-540. doi:10.1080/13678868.2010.520478

Sirianni, P. M., \& Frey, B. A. (2001). Changing a culture: Evaluation of a leadership development program at Mellon Financial Services. International Journal of Training \& Development, 5(4), 290-301.doi:10.111/1468-2419.00141

Smith-Doerr, L., Kemekliene, G., Teutonico, R., Lange, L., Villa-Komaroff, L., Matthiessen-Guyader, L., \& Murray, F. (2011). A global need for women's biotech leadership. Nature Biotechnology, 29(10), 948-949.

Smith, J. A., Flowers, P., \& Larkin, M. (2009). Interpretative phenomenological analysis: Theory, method and research. London, England: Sage.

Stead, V. (2014). The gendered power relations of action learning: A critical analysis of women's reflections on a leadership development programme. Human Resource Development International, 17(4), 416-437. doi:10.1080/13678868.2014.928137

Sturm, R. E., Taylor, S. N., Atwater, L. E., \& Braddy, P. W. (2013). Leader selfawareness: An examination and implications of women's under-prediction. Journal of Organizational Behavior 35, 657-677. doi:10.1002/job.1915

Tessens, L., White, K., \& Web, C. (2011). Senior women in higher education institutions: Perceived development needs and support. Journal Of Higher Education Policy \& Management, 33(6), 653-665. doi:10.1080/1360080X.2011.621191

Trochim, W. M. K., \& Donnelly, J. P. (2008). The research methods knowledge base (3rd ed.). Mason, $\mathrm{OH}$ : Cengage Learning.

Vinnicombe, S., \& Singh, V. (2003). Women-only management training: An essential part of women's leadership development. Journal Of Change Management, 3(4), 294. 
Whatley, L. R., Popa, A. B., \& Kliewer, H. (. (2012). Community and Leadership: The Role of Humility, Rhythm, and Experiential Learning. Journal Of Leadership, Accountability \& Ethics, 9(4), 113-143

Willig, C. (2008). Introducing qualitative research in psychology: Adventures in theory and method (2nd ed.). New York, NY: McGraw-Hill.

Yardley, L. (2008). Demonstrating validity in qualitative psychology. In J. A. Smith

(Ed.), Qualitative psychology: A practical guide to research methods (2nd ed., pp. 235-251). London, England: Sage.

Zahidi, S., \& Ibarra, H. (2010). The Corporate Gender Gap Report 2010. World Economic Forum. Geneva, Switzerland.

\section{Author Biographies}

Dr. Krystal Brue is an Assistant Professor at Cameron University within the Organizational Leadership and Business departments. She holds dual HR certifications as a Senior Human Resource Professional and as a SHRM Senior Certified Professional. Her research areas of interest include leadership, work-life balance, change management, human resource management, and employee engagement. Email: kbrue@ cameron.edu

Shawn Brue holds a Ph.D. in Marriage and Family Therapy. He has been a Licensed Professional Counselor and Licensed Marriage and Family Therapist for over 23 years as well as a clinical supervisor for over 15 years. He serves as a therapist at the Christian Family Counseling Center and an adjunct lecturer at Cameron University. Email: shawnbrue@yahoo.com 